\title{
Políticas Linguísticas e Ensino do Italiano: o Caso da Imigração Italiana na Bahia
}

\author{
Alessandra Caramori* \\ Cristiane Landulfo
}

RESUMO: A língua italiana ingressou em diversas comunidades fora da Itália por várias razões e uma delas é a intensa emigração de cidadãos italianos para os mais longínquos lugares do mundo. A Bahia, estado do nordeste brasileiro, embora poucos saibam, também recebeu, entre os anos de 1950 e 1970, um fluxo significativo de imigrantes italianos que se estabeleceram nos municípios baianos de Boa União, Itiruçu, Jaguaquara e, em especial, Rio Seco, durante o governo de Octávio Mangueira. Nessas localidades, ainda hoje é possível verificar uma forte presença italiana. No entanto, seja pela ineficiência ou inexistência de políticas públicas linguísticas, o ensino do idioma italiano não ocupa um espaço relevante no ensino básico dessas cidades. Este artigo tem, portanto, o propósito de refletir sobre a ausência desse idioma no ensino básico, uma vez que a inclusão de uma língua no currículo escolar deve, a princípio, levar em consideração os fatores relativos às comunidades locais.

PALAVRAS-CHAVE: imigração italiana; políticas linguísticas; ensino do italiano.

ABSTRACT: L'entrata della lingua italiana in diverse comunità fuori d'Italia è avvenuta e avviene ancora per le più svariate ragioni, tra cui l'emigrazione che ha fatto registrare l'espatrio di milioni di cittadini italiani che si sono diretti verso paesi distanti. Lo stato di Bahia, in Brasile, nonostante pochi lo sappiano, tra gli anni '50 e gli anni '70 del secolo scorso, ha ricevuto un fusso significativo di immigrati che si sono stabiliti nei comuni di Boa União, Itiruçu, Jaguaquara e soprattutto Rio Seco, durante il governo di Octávio Mangueira. In queste città è ancora oggi possibile constatare una forte presenza italiana. Tuttavia, a causa dell'inefficienza o della

\footnotetext{
* Universidade Federal da Bahia, Salvador, Bahia (Brasil) - apccaramori@ufba.br / cristiane_landulfo@ufba.br
} 
vera e propria mancanza di una politica linguistica, l'insegnamento della lingua italiana non occupa uno spazio di rilievo nell'istruzione di base in questi comuni. Questo articolo ha quindi come obiettivo riflettere sull'assenza di questa lingua nella scuola primaria, dal momento che l'inclusione della lingua nel programma scolastico dovrebbe prendere in considerazione i fattori relativi alle comunità locali. PAROLE CHIAVE: immigrazione italiana; politica linguistica; insegnamento dell'italiano.

ABSTRACT: For different reasons, including the intense emigration of Italian nationals to the farthest places around the globe, the Italian Language has made its way into a large numbe of communities out of Italy. Although unknown to most, between 1950 and 1970, the State of Bahia, in Brazil, also received an important flux of immigrants, who settled in the Bahian municipalities of Boa União, Itiruçu, Jaguaquara and especially Rio Seco during the government of Octávio Mangueira. Even today it is still possible to note a strong Italian presence there. Nonetheless, whether through inefficient or non-existent public policies for foreign language learning, Italian does not occupy an important space at the elementary-school education level in these cities. This article aims, therefore, at reflecting on the absence of Italian in the region's elementary school system, since language program inclusion in the curriculum should take into account factors related to local communities.

KEYWORDS: Italian immigration; language policies; Italian teaching. 


\section{Introdução}

Atualmente, o idioma italiano vem sendo cada vez mais ensinado em diversos contextos de ensino/aprendizagem, seja como língua estrangeira (doravante LE), seja como segunda língua (doravante L2), tornando-se, desse modo, a quarta língua mais estudada no mundo, conforme declaram Casini e Romanelli (2012), bem como a segunda mais estudada em países como a Hungria e a Rússia, e a primeira na Ucrânia (LANDULFO, 2012).

O ingresso da língua italiana (doravante LI) em diferentes nações ocorreu e ainda ocorre por diferentes razões, tais como: a) o fenômeno da emigração que expatriou milhares de cidadãos italianos para os mais longínquos lugares do mundo; b) ser um dos idiomas oficiais do Vaticano e em função disso estar ligada à religião cristã; c) ser considerada uma língua de "cultura", uma vez que historicamente sempre esteve associada às artes e aos grandes nomes da história da humanidade, como por exemplo, na literatura: Dante Alighieri, Niccolò Machiavelli, Umberto Eco, Italo Calvino, Luigi Pirandello; na pintura: Leonardo da Vinci, Michelangelo, Caravaggio; na música: Antonio Vivaldi, Luciano Pavarotti, Giuseppe Verdi; no cinema: Pier Paolo Pasolini, Federico Fellini; Vittorio De Sica; na arquitetura: Fillipo Brunelleschi, Leon Battista Alberti, Andrea Palladio, entre tantos outros nomes reconhecidamente ilustres. 
Em 2010, uma pesquisa intitulada Italiano 2010. Lingua e cultura italiana all'estero [Língua e cultura italiana no exterior] da qual participaram 89 Istituti Italiani di Cultura (IIC) ativos em diferentes regiões do mundo demostrou que 6.429 cursos de italiano são realizados por esses institutos em todo o mundo1. Além disso, as informações encontradas comprovam o progresso no ensino do italiano em cidades nas quais não havia sido verificada a existência de nenhum curso, como por exemplo, na cidade de Kyoto, onde foi registrada a presença de 102 cursos de italiano.

No Brasil, o número de pessoas interessadas em estudar a LI vem crescendo cada vez mais. Segundo o último censo do Rapporto Italiani nel Mondo [Relatório Italianos no Mundo], realizado pela Fondazione Migranti [Fundação Migrantes] juntamente com um comitê formado por diversas entidades e com a colaboração de estudiosos de diferentes procedências, coordenados pelo Dossier Statistico Immigrazione [Dossiê Estatístico da Imigração], um dos fatores desse interesse, deve-se provavelmente ao fato de viverem no Brasil cerca de 31 milhões de descendentes, o que corresponde a mais de $15 \%$ da população brasileira.

Conforme declaram Casini e Romanelli (2012), é mais frequente encontrar o ensino da LI nos estados para os quais se dirigiram milhões de imigrantes ao longo dos séculos, tais como: São Paulo, Rio Grande do Sul, Espírito Santo e Santa Catarina. Contudo, o que pouca gente sabe é que houve uma importante imigração italiana no Estado da Bahia e é a isso que será dedicada a próxima seção.

\section{Imigração Italiana na Bahia}

De acordo com o Anuário Estatístico do Ministero Affari Esteri [Ministério das Relações Exteriores da Itália, doravante MAE], publicado em 2012, milhares de italianos e seus descendentes vivem em diversas partes do mundo. Bertonha, em seu livro intitulado A imigração italiana no Brasil, informa que no século XX existiam "italianos e seus descendentes em toda a América Latina, nas colônias europeias da África e da Ásia e no Leste Europeu, além de grupos consideráveis no norte da África, especialmente na Tunísia, no Egito, além do continente australiano" (2004, p. 9-10). Sobre isso, Benedini e Arquilla explicam:

A importância histórica da emigração italiana, o maior êxodo da história moderna, é resumível em poucos números: de 1869 a 1970, mais de vinte milhões de pessoas

1 Participaram da pesquisa, entre outros, os IICs das seguintes regiões: Leste Europeu (Budapeste, Cracóvia, Kiev, Ljubljana, Varsóvia); Europa Ocidental (Hamburgo, Barcelona, Innsbruck, Stuttgart); Norte da África (Rabat, Trípoli) e América Latina (Cidade da Guatemala, Montevidéu, Rio de Janeiro). 
(correspondentes a mais de um terço da população atual da península) deixaram a Itália em direção a outros países, pouco menos da metade desses se encaminharam para nações extraeuropeias. Em 1913, esse fenômeno alcançou o seu ápice: 870.000 partidas em um único ano (BENEDINI e ARQUILLA, 2015, p. 6-7).

Bertonha (2004) apresenta uma tabela, resumindo em números o fenômeno do êxodo italiano para diferentes países, mas alerta para o fato de que esses números devem ser observados cuidadosamente, uma vez que foram registradas apenas as entradas dos italianos e não suas saídas.

Tabela 1 - Os italianos em diferentes países

\begin{tabular}{l|l|l|l}
\multicolumn{5}{c}{ Emigração italiana 1870-1970 (em milhões) } \\
\hline Estados Unidos & 5,6 & Canadá & 0,6 \\
\hline França & 4,1 & Bélgica & 0,5 \\
\hline Suiça & 3,0 & Austrália & 0,4 \\
\hline Argentina & 2,9 & Venezuela & 0,2 \\
\hline Alemanha & 2,4 & Grã-Bretanha & 0,2 \\
\hline Brasil & 1,5 & Europa & 125 \\
\hline Império Austro-húngaro & 1,1 & América e Austrália & 11,5 \\
\hline
\end{tabular}

Fonte: Bertonha (2004, p. 10).

Ao Brasil, país no qual vive até hoje a maior comunidade mundial de descendentes de italianos, chegou, entre 1884 e 1933, conforme Benedini e Arquilla, a maior parte dos cidadãos da Península, que chegou a 1.401.335, assim distribuídos:

510.533 entre 1884 e $1893,537.784$ entre 1894 e 1903, 196.521 entre 1904 e 1913, 86.320 entre 1914 e 1923 e 70.177 entre 1924 e 1933 . No período de 1884-1903, ou seja, até um ano após entrar em vigor o Decreto Prinetti, os italianos constituíam $60,39 \%$ do total dos estrangeiros emigrados no "Gigante da América do Sul" (2015, p. 65).

Após a Segunda Guerra Mundial, inicia-se uma nova fase migratória que, embora tenha seguido as mesmas rotas percorridas pelas primeiras (estados do Sul e do Sudeste brasileiro), 
é caracterizada por uma exceção: a vinda de 458 agricultores que partiram das regiões do Abruzzo, do Molise e das Marcas e que se estabeleceram, entre os anos de 1950 e 1970, nas colônias agrícolas da Bahia.

Uma intensa e extensa pesquisa realizada por Giuseppe Benedini e Matteo Arquilla, cujo resultado foi a publicação do já citado livro intitulado Na toca do Jaguar, história da imigração italiana nas colônias agrícolas da Bahia, relata com riqueza de detalhes como se organizaram as comunidades italianas no interior da Bahia, principalmente, nas colônias agrícolas formadas após a segunda guerra mundial, durante o governo de Octávio Mangabeira.

$\mathrm{O}$ fato é que um acordo estipulado entre governo local e a cooperativa Società Cooperativa Lavoratori Agricoli per il Venezuela [Sociedade Cooperativa de Trabalhadores Agrícolas para a Venezuela - SCLAPIV] possibilitou a vinda, inicialmente de jovens agricultores e, posteriormente, de famílias compostas por indivíduos pertencentes a três ou quatro gerações, todos em busca de uma vida melhor. Isso foi possível devido aos incentivos à imigração italiana, promovidos pela Secretaria de Agricultura da Bahia e pelo Ministério da Agricultura, uma vez que este último, em 18 de outubro de 1949, disponibilizou um montante para a constituição de núcleos coloniais.

Desse modo nasceram, no biênio 1949-1950, as colônias de Boa União, próximo a Camaçari, Rio Seco, atualmente Conceição do Jacuípe, Itiruçu e a colônia federal Jaguaquara. O nome desta última localidade, rebatizada assim em tupi-guarani em 1914, significa Toca da Onça, nome que deu origem ao título do livro acima mencionado, visto que essa cidade está fortemente ligada à presença do grupo bastante numeroso de famílias italianas.

É importante informar que, conforme escrevem os autores, esses assentamentos

refletiam a nova orientação das políticas agrícolas na Bahia, que os queriam voltados para o mercado interno do estado e abertos à chegada dos estrangeiros. Todos foram destinados à hortifruticultura e povoados, ao menos pela metade, por imigrados europeus (BENEDINI e ARQUILLA, 2015, p.125).

Foram escolhidas essas localidades por critérios climáticos e para favorecer a adaptação do imigrante europeu, mas o que o governo brasileiro buscava, na verdade, era mão de obra especializada, que conhecesse técnicas agrícolas para tornar viável a produção de itens carentes na região, como couve-flor, brócolis, tomate, beterraba e cenoura. 
Ainda hoje, o mercado produtor Ceasa-Jaguaquara é um dos mais importantes mercados atacadistas hortifrutigranjeiros da Bahia atendendo a várias regiões do país2. É por essa razão que os autores da obra que narra a epopeia desses imigrantes afirmam que

No geral foi uma transação vantajosa para ambas as partes: de um lado o governo baiano que assegurava a chegada de um numeroso contingente de agricultores especializados provenientes da Europa; de outro lado, os dirigentes da SCLAPIV, depois do fracasso das expedições na Venezuela e na região Sudeste do Brasil, podiam finalmente alentar os associados, não mais com vagas promessas, mas com uma proposta concreta. Os termos estipulados com a Secretaria liberavam, também, a cooperativa de qualquer ônus pela compra de terra (BENEDINI e ARQUILLA, 2015, p. 165-166).

Logo depois da chegada e do período de adaptação dos imigrantes italianos, a presença italiana na Bahia do centro-sul consolidou-se e, ainda segundo Benedini e Arquilla (2015), já dura há um século e meio, o que faz dessa região, certamente, a mais 'italiana' do Nordeste.

Em sua obra, os autores ainda declaram que nos países em que esse idioma chegou juntamente com os imigrantes, como no Brasil, geralmente se criou uma rede de estruturas em torno dela, como escolas e associações para sua divulgação.

Foram enviados técnicos, agrônomos, professores, companhias filarmônicas e material de propaganda com o objetivo de incentivar a valorização da língua e da cultura italiana e de desenvolver associações de âmbito nacional. Surgiram desse modo, também no Brasil, escolas, sindicatos, associações de ajuda mútua, instalações de lazer e recreação para depois do trabalho [...] (BENEDINI e ARQUILLA, 2015, p. 65, grifo nosso).

De fato, em nossa viagem realizada em setembro de 2015, verificamos traços de italianidade tanto em Jaguaquara como em Itiruçu. Nessas duas localidades, visitamos restaurantes com comida tipicamente italiana de excelente qualidade, percebemos que muitos estabelecimentos comerciais possuem nomes italianos em suas fachadas e, principalmente, constatamos a presença ainda viva de alguns italianos que vieram durante o processo migratório promovido pelo governo baiano, bem como de seus descendentes.

2 Essas informações podem ser encontradas no Blog de marcofran.com. 
Entretanto, em conversas com professores e diretores de escolas locais fomos informadas sobre o fato que, apesar de existir na cidade o interesse pela aprendizagem da LI que possui na região o valor de língua de herança3, não há nenhuma escola de ensino básico, pública ou privada, que ofereça em seu currículo o ensino do idioma. Isso significa que à comunidade local, em parte proveniente da Itália, não é dado o direito de aprender a língua de seus antepassados. É sobre essa questão que discorreremos na próxima seção.

\section{O ensino do italiano e as políticas linguísticas no Brasil}

As políticas públicas, no que se refere ao ensino das línguas estrangeiras, abarcam uma gama de decisões que vão desde a escolha de um determinado lugar onde uma língua deve ser falada, como por exemplo a imposição de uma língua oficial, até questões relativas ao ensino e à aprendizagem de diferentes línguas. Ou seja, as ações dos professores são determinadas pelas leis de diretrizes governamentais, pelos projetos de secretarias de educação dos estados ou, ainda, em alguns casos, pelo trabalho de associações de professores.

O ensino de qualquer língua é, portanto, determinado pelas políticas linguísticas de um dado país. No Brasil, atualmente, dois documentos vigentes estabelecem os critérios para as ações educacionais em diversos níveis: os Parâmetros Curriculares Nacionais (doravante PCN) e a Lei de Diretrizes e Bases da Educação (doravante LDB). Os PCN, criados em 1996, são referenciais elaborados pelo governo federal para orientar as equipes escolares na execução de seus trabalhos, com diretrizes voltadas, sobretudo, para a estruturação e reestruturação dos currículos escolares de todo território brasileiro, sendo obrigatórias para a rede pública e opcionais para as instituições da rede privada. Voltados para o ensino fundamental e para o ensino médio, esses documentos são divididos, respectivamente, em seis volumes que apresentam as áreas do conhecimento, como: língua portuguesa, matemática, ciências naturais, história, geografia, arte e educação física, e em três áreas - Linguagens, Códigos e suas Tecnologias, Ciências da Natureza, Matemática e suas Tecnologias e Ciências Humanas e suas Tecnologias. Logo nas primeiras páginas da seção voltada para o ensino de LE do terceiro e quarto ciclos do ensino fundamental, verifica-se a menção à Declaração de Direitos linguísticos, quando se afirma que todo cidadão tem direito à aprendizagem de uma LE (BRASIL, 1998).

A aprendizagem de uma LE, juntamente com a língua materna, é um direito de todo cidadão, conforme expresso na Lei de Diretrizes e Bases e na Declaração Universal dos Direitos

3 Língua de herança é a língua que é ensinada e utilizada pelo indivíduo, mas que não é própria do local onde ele resida, como exemplo, o Português ensinado a filhos de brasileiros imigrados no exterior ou de filhos de italianos que residem no Brasil (GUIMARÂES, 2007, p. 64). 
Linguísticos, publicada pelo Centro Internacional para Minorias Étnicas e Nações (Ciemen) e pelo PEN-Club Internacional. O distanciamento proporcionado pelo envolvimento do aluno no uso de uma língua diferente o ajuda a aumentar sua autopercepção como ser humano e cidadão. Ao entender o outro e sua alteridade pela aprendizagem de uma LE, ele aprende mais sobre si mesmo e sobre um mundo plural, marcado por valores culturais diferentes e maneiras diversas de organização política e social. É por isso que a escola não pode mais se omitir em relação a essa aprendizagem (BRASIL, 1998, p. 19).

O referido documento relata ainda o fato de nem sempre ser possível incluir no currículo escolar mais que uma LE e, por isso, aponta três fatores que podem servir como ponto de partida para definir qual ou quais línguas estrangeiras incluir no currículo:

1. Fatores históricos - relacionados ao papel que uma língua específica representa em certos momentos da história da humanidade. Um caso típico é representado pelo inglês em função do poder e da influência da economia norte-americana na sociedade contemporânea e que, conforme afirma Siqueira (2008), alcançou o status de língua internacional;

2. Fatores relativos às comunidades locais - a convivência entre comunidades locais e imigrantes ou indígenas pode ser um critério para a inclusão de determinada língua no currículo escolar;

3. Fatores relativos à tradição - o papel que determinadas línguas estrangeiras tradicionalmente desempenham nas relações culturais entre os países pode ser um fator a ser considerado (BRASIL, 1998, p. 22).

Entre esses fatores postulados pelos PCN, é importante refletir sobre o terceiro: por que é relevante levar em consideração a tradição? Ela tem que ser mantida em qualquer situação? Ora, em muitos casos, a tradição precisa, inclusive, ser modificada em virtude do momento histórico e social no qual se encontram os indivíduos de uma determinada sociedade. Além disso, sendo a tradição algo que perdura no tempo por ser transmitida de geração em geração, como explicar o fato de o latim, que durante muito tempo foi a língua de prestígio ensinada nas escolas públicas de todo o Brasil, ter sido extinto dos currículos escolares? Ou, ainda, por que a opção pelo ensino do inglês em comunidades nas quais as línguas dos imigrantes são faladas e, por tradição, deveriam ser ensinadas? Observando tudo isso, entendemos que os fatores 
históricos e aqueles relativos às comunidades locais já contemplam as razões que podem levar uma dada língua a ser escolhida em detrimento de outra.

Passemos agora à LDB que foi aprovada em dezembro de 1996 com o nº 9.394/1996 e é composta por 92 artigos que versam sobre os mais diversos temas da educação brasileira, desde o ensino infantil até o ensino superior. Seu art. $36^{\circ}$, inciso III, traz uma importante informação: "será incluída uma língua estrangeira moderna, como disciplina obrigatória, escolhida pela comunidade escolar, e uma segunda, em caráter optativo, dentro das disponibilidades da instituição" (LDB, 2005, p. 19). Como se vê, a LDB não estabelece a LE que deve ser ensinada, facultando sua escolha às comunidades.

Diante do exposto pelos documentos oficiais e rememorando quanto afirma Zorzan (2015), em sua dissertação de mestrado, fazemos os seguintes questionamentos: (1) Por que o italiano não ocupa um espaço maior no contexto do ensino público brasileiro, assim como outras línguas sob a tutela do Estado? (2) Levando em consideração os fatores relativos às comunidades locais, por que as línguas africanas não possuem maior espaço nas escolas baianas, uma vez que esse estado brasileiro é reconhecido como aquele que possui maior número de descendentes africanos? (3) Por que a LI não é ofertada nas escolas das cidades onde foram estabelecidas as colônias italianas, considerando que a relação com as comunidades locais pode ser um dos fatores para a escolha de uma língua ensinada nas escolas?

É sempre bom lembrar que "lugar de aprender LE é na escola básica" (PNLD, 2011, p. 11) e que, além disso, dar a todos os estudantes a possibilidade de aprender na própria escola o idioma que desejam é uma forma de "deselitizar" o ensino de línguas no Brasil.

Democratizar o acesso às línguas estrangeiras é trazer para a agenda escolar um tema que vem adquirindo crescente importância na vida contemporânea: a diversidade cultural que traz à tona discussões acerca de práticas racistas provenientes de preconceitos, estereótipos, intolerância cultural e incapacidade de compreender as diferentes dinâmicas das diversas culturas dos mais variados povos.

\section{Palavras conclusivas}

Ainda que seja importante conhecer mais a história da imigração italiana no Brasil, uma vez que aqui vivem muitos descendentes, que possuem o direito de estudar sua língua de herança, compreendemos também que é preciso ultrapassar o "véu que separa o italiano entendido como 
língua de imigrante do italiano entendido como língua do mundo, entre as mais representativas do ponto de vista cultural" (ROMANELLI; CASINI, 2012, p. 15,). Pois, embora a LI seja, notadamente, uma língua da imigração, ela não é apenas isso. Seria, assim, essencial expandir o espaço linguístico do italiano para além desse estereotipo.

É importante salientar que o mapeamento feito por Zorzan (2015) mostrou que, nos dias de hoje, o ensino do idioma italiano está presente nas escolas de ensino básico de diversos estados brasileiros (Acre, Pernambuco, Rondônia, São Paulo, Goiás, Minas Gerais, Espírito Santo, Rio de Janeiro, Rio Grande do Sul, Santa Catarina, Espírito Santo, Paraná) ainda que em algumas cidades essa oferta ocorra por meio de iniciativas de instituições privadas e em número reduzido. Infelizmente, essa realidade ainda não chegou ao estado da Bahia.

Entendemos que o acesso ao aprendizado de qualquer língua deva ser direito de todo cidadão e que o lugar de aprender uma LE deva ser a escola. Certamente, o caminho para a promoção desse ensino perpassa muitas esferas, tais como o Estado (responsável maior pelo planejamento linguístico de um país) e as instituições de ensino. Contudo, em relação ao idioma italiano, tema deste artigo, cabem aos docentes, bem como aos pesquisadores da área de Italianística, ações que promovam a democratização do ensino do idioma. É por isso que este artigo foi escrito: para incentivar a reflexão sobre as questões aqui pontuadas, mas, sobretudo, para dar um pontapé inicial às ações que devem ser ainda promovidas a fim de que o aprendizado do italiano se torne, de fato, um direito de todos.

\section{Referências}

BENEDINI, G. F.; ARQUILLA, M. Na Toca do Jaguar: História da Imigração italiana nas colônias agrícolas da Bahia. Tradução de LANDULFO, C.M.C.L.S. Viterbo: Edizioni Sette Città, 2015.

BERTONHA, J. F. A imigração italiana no Brasil. São Paulo: Saraiva, 2004.

BRASIL. Secretaria de Educação Fundamental. Parâmetros Curriculares Nacionais/Secretaria de Educação Fundamental. Brasília: MEC/SEF, 1998.

Lei n. 9.394, de 20 de dezembro de 1996, de Diretrizes e Bases da Educação Nacional. Programa Nacional do Livro Didático (PNLD). Brasília: MEC, 2011.

CASINI, M.C.; ROMANELLI, S. Italianistica in Brasile: ricerca di prospettive e prospettive di ricerca. In.iT, $\mathrm{n}^{\circ} 27,2012$, p.15-18.

GUIMARÃES, E. Política de línguas na linguística brasileira. In: ORLANDI, E. (org.) Política Linguística no Brasil. Campinas, SP: Editora Pontes, 2007. 
LANDULFO, C.M.C.L.S. Cultura de aprender: investigando as crenças e as ações dos alunos de língua italiana da UFBA. Dissertação de mestrado. Universidade Federal da Bahia (UFBA), 2012. Disponível em: https://repositorio.ufba.br/ri/bitstream/ri/8619/1/Cristiane\%20Maria\%20C\%20L\%20L\%20 de\%20Sousa.pdf

ZORZAN. F. J. A. O ensino de italiano (LE) em contexto público no Brasil: mapeamento e estudo de caso. Dissertação de mestrado. Universidade de São Paulo (USP), 2015. Disponível em: http://www. teses.usp.br/teses/disponiveis/8/8148/tde-26052015-111630/pt-br.php.

Recebido em 06/05/2016

Aprovado em 28/09/2016 